\title{
Dental Implants in Osteoporotic Patients Taking Oral Bisphophonates: A Literature Review
}

\author{
Nuti N*, Baldini N, D’Elia C, Gabriele G, Gennaro \\ $P$ and Ferrari $M$ \\ Department of Medical Biotechnology, University of \\ Siena, Italy \\ *Corresponding author: Niccolò Nuti, Department of \\ Medical Biotechnology, University of Siena, Italy
}

Received: February 03, 2017; Accepted: March 14, 2017; Published: April 03, 2017

\begin{abstract}
Objective: Osteoporosis is a systemic disorder characterized by generalized decrease in bone mineral density that can eventually result in fragility fracture. Bisphosphonates have been used in the treatment of osteoporosis for many years in order to inhibit bone resorption. Unfortunately, the use of bisphosphonates has been found to be associated with several adverse events in patients where dental pathologies were present. For this reason, an increased attention has been recommended in those patients where bisphosphonates have been assumed and where dental therapies are mandatory. The aim of this article is to focus on the aspects of implant therapy in patients under bisphosphonates treatment and to produce a bibliographic review of dental implants placed in osteoporotic/osteopenic patients under treatment with oral bisphosphonates.
\end{abstract}

Materials and Methods: The literature review was performed on PUBMED, MEDLINE using as search terms: oral bisphosphonates, dental implants, osteoporosis/osteopenia, osteonecrosis of the jaws (ONJ).

Conclusions: In conclusion the analysis of the studies shows that the therapy with oral bisphosphonates does not affect osteointegration of dental implants and in most cases determines a low risk of ONJ.

Keywords: Oral bisphosphonates; Dental implants; Osteoporosis/ osteopenia; Osteonecrosis of the jaws (ONJ)

\section{Introduction}

Osteoporosis is a systemic skeletal disorder characterized by skeletal fragility, and macro/micro-architectural modifications [1]. Osteoporosis is one of the most common chronic diseases referred in $1 / 3$ postmenopausal women and $1 / 5$, men over the age of 50 years (European Parliament Osteoporosis Interest Group and EU Osteoporosis Consultation Panel 2004) [2]. For example in Europe, the USA and Japan, osteoporosis is estimated to affect 75 million people [3] ; currently, it is estimated that over 200 million people worldwide suffer from this disease, and the incidence of osteoporosis increases exponentially after the age of 50 [4] . In fact one third of women and one-fifth of men over 50 had experienced osteoporotic fractures $[5,6]$. The risk of hip, forearm and vertebrae fracture is approximately $40 \%$ the same as the risk of cardiovascular disease [6]. According to some authors, $40 \%$ of women $[7,8]$ or $50 \%$ of women over 50 [9] and up to $29 \%$ of men may sustain an osteoporotic fracture. A higher prevalence of fragility fractures has been described in white populations [10], especially in non Hispanic-Caucasians [11]; lower rates have been found among black populations [10]. In Europe, the Scandinavian countries have the highest prevalence of fragility fractures [12]. Although it is widely recognized that low bone mass is not the only determinant of bone fragility, the strength of the skeleton is influenced by other bone tissue properties, collectively named "bone quality" $[13,14]$. The mean change of bone remodelling pattern in osteoporosis patients resulted in perforation of trabecular plates and loss of cancellous trabecular elements with consequent bone mineral density. Established risk factors for osteoporosis include older age; female gender; post-menopause; Caucasian or Asian race; a low body mass index; cigarette use; alcoholism; inadequate calcium and vitamin D intakes; physical inactivity; taking medications such as glucocorticoids and anticonvulsants; and anorexia nervosa $[15,16]$.

The current medications approved for osteoporosis include calcium, vitamin D, bisphosphonates, parathyroid hormone, selective estrogen, receptor modulators, calcitonin, hormone therapy, denosumab and strontium ranelate [17]. Bisphosphonates drugs have now been in use for more than 10 years, and the number of patients who have used them or continue to use them is on the increase. These drugs are commonly prescribed to stabilize bone loss caused by osteoporosis in millions of postmenopausal women [18]. The term "bisphosphonates" is derived from the base of the drug, namely two phosphate (PO3) groups covalently linked to a central carbon. The carbon atom confers resistance to hydrolysis and allows two R sidechains to attach. The short side chain, R1 influences the chemical properties, whereas the long side chain R2 determines the mode of action and the strength of bisphosphonates. Bisphophonates inhibit osteoclasts by two mechanisms, depending on whether the R2 side chain contains nitrogen side groups. Bisphosphonates can be divided into two groups:

- The nonaminobisphophonates (etidronate, clodronate and tiludronate) lack a nitrogen in their side chains and are able to inactivate nonhydrolyzable ATP analogs that interfere with osteoclast activity and so induces apoptosis.

- The aminobisphosphonates (pamidronate, alendronate, ibandronate, risendronate and zoledronate) with nitrogen containing side groups, have four activities: inactivation of ATP; inhibition of
Austin J Dent - Volume 4 Issue 3 - 2017

ISSN : 2381-9189 | www.austinpublishing group.com

Nuti et al. (C) All rights are reserved
Citation: Nuti N, Baldini N, D'Elia C, Gabriele G, Gennaro P and Ferrari M. Dental Implants in Osteoporotic Patients Taking Oral Bisphophonates: A Literature Review. Austin J Dent. 2017; 4(3): 1071 
farnesyldiphosphonate synthase resulting in cytoskeletal disruption, dysregolation of intracellular transport and inhibition of cell proliferation; reduction of osteoclast recruitment; and induction of osteoblast to produce an osteoclast-inhibiting factor. It is estimated that in 2010 there were approximately 700,000 prescriptions of bisphosphonates per week.

Bisphophonates are available in oral doses (daily, weekly, monthly and quarterly) and in intravenous yearly doses [17]. There are differences between bisphophonates administered intravenously and those taken orally.

\section{Intravenous bisphosphonates}

Intravenous bisphosphonates are antiresorptive medications used to manage cancer-related conditions including hypercalcemia of malignancy, skeletal-related events (SRE) associated with bone metastases in the context of solid tumors such as breast cancer, prostate cancer and lung cancers, and for the management of lytic lesions in the setting of multiple myeloma $[19,20]$ While the potential for bisphosphonates to improve cancer-specific survival remains controversial, these medications have had a significant positive effect on the quality of life for patients with advanced cancer involving the skeleton.

\section{Oral bisphosphonates}

Oral bisphosphonates are approved for treatment of osteoporosis and are frequently used to treat osteopenia as well [21]. They are also used for a variety of less common conditions such as Paget's disease of bone, and osteogenesis imperfecta [22,23]. The most common use, however, is for osteopenia and osteoporosis [24,25].

An increase in life expectancy of the world population has been observed [26,27]. Like osteoporosis, in this context, the edentulism affects the elderly population around the world (from $11 \%$ to $44 \%$ ) [28]; US data show that the number of edentulous patients in 2020 will be around 38 million people [29]. The use of dental implants constitutes a well-documented treatment-modality [30] and represents an alternative to rehabilitate these patient aesthetically and functionally and present high predictability. Success becomes more predictable when adequate local and systemic conditions are present to provide bone healing during the osteointegration process $[31,32]$. Since the increase of life is accompanied inexorably with the greatest chance of having bone diseases, frequently in clinical practice we might treat osteoporotic subjects with dental implants. As written above most osteoporotic patients are taking oral bisphosphonates such as alendronate, risendronate or ibandronate. Bisphosphonates treatment was first identified by Marx in 2003 as a possible contributor to osteonecrosis of the jaw, a serious dental-medical complication that is seen among individuals undergoing invasive dental procedures such as extraction and implant placement [33] Oral surgical procedures, including dental implant placements are known to be the most relevant risk factors for the ONJ development in cancer patients taking intravenous bisphosphonates; the majority of ONJ cases reported in the scientific literature after dental implants placement and oral surgery such as dental extraction include patients receiving intravenous bisphosphonates for bone metastases and multiple myeloma [34]. Furthermore, with the introduction of nBPs, namely zoledronate (zoledronic acid), which has a powerful bone resorption inhibitor, the incidence of complications associated with intra-venous BPs has grown $[35,36]$. The incidence of BRONJ after dental extractions range from $1 \%$ to $11 \%$ in breast cancer patients, $3 \%$ to $17 \%$ in multiple myeloma patients, and $3 \%$ to $18 \%$ in prostate cancer patients $[37,38]$. Kühl, et al. selected 23 studies and reported an incidence of BRONJ equal to $0-11.5 \%$ in therapies up to one year and $0-27.5 \%$ in therapies lasting from 1 to 4 years with the use of zoledronate [36]. The current guidelines contraindicate the use of dental implants in cancer patients taking intravenous bisphosphonates [39]. Mínguez-Serra, et al. [40] suggested the avoidance of dental implant procedures in patients that have been receiving intravenous BPs. This is in accordance with several studies where it has been shown that the combined use of oral and intravenous BP, have determined cases of osteonecrosis [41-43].

The estimated incidence of orally administered bisphosphonates related osteonecrosis of the jaws for patient treated with weekly alendronate is 0.01 to $0.04 \%$ [44]; furthermore, when administered intravenously, bisphosphonate loads bone and accumulates in bone 142.8 times faster than when administered orally [45]. For this reason, dental implant placement is not contraindicated in patients taking oral bisphosphonates, but oral surgical procedures are considered the major risk factor of development of $\mathrm{ONJ}$ in patients under therapy with this drugs [46]. The aim of this article is to produce a bibliographic review of dental implants placed in osteoporotic/ osteopenic patients under treatment with oral bisphosphonates.

\section{Materials and Methods}

According to our aim, a literature review was performed on PUBMED, MED-LINE using as search terms: oral bisphosphonates, dental implants, osteoporosis/osteopenia, osteonecrosis of the jaws. Our research discovered 166 papers of which these only 22, following the inclusion and esclusion criteria, were eligible for our literature review.

The inclusion parameters were:

- Studies concerning humans.

- Papers where dental implants were inserted in patients taking bisphosphonates orally.

- Papers with patients for the treatment of osteoporosis/ osteopenia.

- We selected for our literature review both case series and case reports.

The esclusion paramaters were:

- $\quad$ Animal studies.

- Papers where dental implants were inserted in patients taking bisphosphonates intravenously.

- Papers with patients for the treatment of malignant hypercalcemia, skeletal complications suffered by patients with Paget's disease or myeloma and for the treatment of bone metastasis derived from various cancers.

\section{Results}

Following the inclusion and esclusion criteria, 22 papers were eligible for our literature review; we preferred to perform a literature 
Table 1: Published studies of oral bisphosphonates and implant placement.

\begin{tabular}{|c|c|c|c|c|c|}
\hline $\begin{array}{c}\text { Author } \\
\text { (year) }\end{array}$ & N.patients & N. implants & Failure & ONJ & Survival rate \\
\hline$[47]$ & 25 & 102 & 0 & No & $100 \%$ \\
\hline$[48]$ & 61 & 169 & 0 & No & $100 \%$ \\
\hline$[49]$ & 115 & 468 & 2 & No & $99,6 \%$ \\
\hline$[50]$ & 41 & 101 & 5 & No & $95 \%$ \\
\hline$[51]$ & 11 & 35 & 5 & No & $86,7 \%$ \\
\hline$[52]$ & 55 & 121 & 1 & No & $99,1 \%$ \\
\hline$[53]$ & 21 & 46 & 0 & No & $100 \%$ \\
\hline$[54]$ & 22 & 75 & 1 & No & $98,7 \%$ \\
\hline$[55]$ & 26 & 56 & 3 & No & $94,1 \%$ \\
\hline$[56]$ & 100 & 153 & 10 & No & $93,5 \%$ \\
\hline$[57]$ & 235 & 1267 & 16 & No & $98,7 \%$ \\
\hline$[58]$ & 32 & 98 & 1 & No & $98 \%$ \\
\hline
\end{tabular}

review rather than a systematic review or meta-analysis because there were many variables in the studies that we have carefully selected, represented by the number of selected patients, the number of implants placed, the follow-up period and finally the type of drug taken by patients. In the selected studies, the main complication was represented by the osteonecrosis of the jaws (ONJ); in fact we have divided the studies into two tables. The first contains all studies where there has not been this kind of complication, in the second, where it is manifested.

\section{Discussion}

As reported before bisphosphonates treatment (oral and intravenous) was identified as a possible contributor to ONJ, especially after oral surgical procedures, including dental implant placement; however, the incidence of BRONJ (bisphosphonates related osteonecrosis of the jaws) seems to be low in patients treated with oral bisphophonates. For example, in 2007, Fugazzotto, et al. published the outcome of 169 implants placed in 61 patients treated with oral bisphosphonates during an average period of 3.3 years, showed no cases of BRONJ during follow-up (12-24 months), and no implant was lost. He reported a case of bone exposure of the torus around a post-extraction implant, that closed spontaneously after four weeks [48]. Grant, et al. described a case- series of 468 implants placed in 115 patients, of which 89 took bisphosphonates orally prior to implant surgery and 33 of them for more than three years. No cases of BRONJ appeared and there were only two implants that failed to osteointegrate but of these, one patient had taken oral bisphosphonates for four years preceding surgery [49]. A large survey of 46 dentists in South Australia gathered information on about 28, 000 implants in 16, 000 patients over a 10 -year period. The estimated prevalence of BRONJ in patients treated with oral bisphosphonates was $0.89 \%$ [70]. Furthermore, recent studies used oral bisphosphonates to assess the osteointegration of dental implants; some authors reported that clodronate could be useful in the maintenance of primary stability [71-73]. Zuffetti, et al. administred a 3\% clodronate solution mixed with a surfactant (Tween-20) at a 1:3 ratio both at the implant surface and at the implant site, reporting that oral BPs may positively affect implant survival in the preloading and postloading phases in partially and fully edentulous patients [74].
Table 2: Published cases of ONJ after dental implant placement in patient taking oral bisphosphonates.

*The type of oral bisphosphonate is not specified by the authors.

\begin{tabular}{|c|c|c|c|c|}
\hline Author (year) & Disease & Drug & Duration & N.implants \\
\hline [59] & Osteoporosis & Risedronate & $2.5 \mathrm{yr}$ & 10 \\
\hline$[60]$ & Osteoporosis & Alendronate & $10 \mathrm{yr}$ & 3 \\
\hline [61] & Osteoporosis & Alendronate & $5,5 \mathrm{yr}$ & 2 \\
\hline [62] & $\begin{array}{l}\text { Osteoporosis } \\
\text { Osteoporosis }\end{array}$ & $\begin{array}{l}\text { Alendronate } \\
\text { Alendronate }\end{array}$ & $\begin{array}{l}\text { NA } \\
\text { NA }\end{array}$ & $\begin{array}{l}\text { NA } \\
\text { NA }\end{array}$ \\
\hline [63] & Osteoporosis & OralBp* & NA & NA \\
\hline$[64]$ & Osteoporosis & Alendronate & $5 \mathrm{yr}$ & 6 \\
\hline [65] & Osteoporosis & Alendronate & $5 \mathrm{yr}$ & 2 \\
\hline$[66]$ & Osteoporosis & Alendronate & $9 \mathrm{yr}$ & 1 \\
\hline [67] & Osteoporosis & Alendronate & $6,6 \mathrm{yr}$ & 1 \\
\hline $\begin{array}{l}{[68]} \\
{[69]}\end{array}$ & $\begin{array}{c}\text { Osteoporosis } \\
\text { Osteoporosis } \\
\text { Osteoarthritis- } \\
\text { Osteoporosis } \\
\text { Polymialgya } \\
\text { rheumatica }\end{array}$ & $\begin{array}{l}\text { Risedronate } \\
\text { Alendronate } \\
\text { Ibandronate } \\
\text { Risedronate }\end{array}$ & $\begin{array}{c}2,5 \mathrm{yr} \\
\text { AVG } 3,7 \mathrm{yr} \\
\text { AVG } 2,8 \mathrm{yr} \\
4 \mathrm{yr}\end{array}$ & 1 \\
\hline
\end{tabular}

Nevertheless, we must also consider the cases of implant failure and BRONJ in patients under treatment with oral bisphosphonates. For example Wang, et al. showed a case of BRONJ in one of the five mandibular implants in a patient who had taken alendronate orally for a period of more than ten years [70]. Similarly Marx, et al. reported two cases of osteonecrosis resulting from implant surgery in patients who had taken bisphosphonates orally over periods of more than three years [61]. Bedogni, et al. in 2010 published a case report where a case of necrotic bone was underlined around an implant two years after the surgery in a patient of 63 years treated with a $70 \mathrm{mg}$ of alendronate weekly for about seven years [66]; but it is important to emphasize that in all cases presented the patients are taking the drug for a period exceed three years. In fact, interestingly a systematic review conducted by Kumar, et al. reported that the implant survival rates ranged between $95 \%$ and $100 \%$ in the case of bisphosphonates users and $96.5 \%$ to $99.2 \%$ in the non-users; concluding that short term bisphopshonate therapy does not increase or decrease the survival rate of dental implants in bisphosphonates users as compared to nonusers [75]. In fact, several retrospective studies above cited did not find a relationship between the long term use of oral bisphosphonates and implant failure or occurrence of ONJ, but the cases above reported suggest that all the patients reported ONJ taking medications for a period exceeding four years $[33,59,61,65-67]$. Essentially, for patients receiving oral bisphosphonates therapy to manage osteoporosis, the prevalence of ONJ increases over time from near 0 at baseline to $0.21 \%$ after four or more years of bisphosphonate exposure. The median duration of bisphosphonate exposure for patients with ONJ and ONJ-like features was 4.4 years. For patients without ONJ, the median exposure to oral bisphosphonates was 3.5 years [76,77]. The American Association of Oral and Maxillofacial Surgeons recommendations for implant placement are [78]. For individuals who have taken an oral bisphosphonate for less than four years and have no clinical risk factors, no alteration or delay in the planned surgery is necessary.

It is suggested that if dental implants are placed, informed consent should be provided related to possible long-term implant failure and 
the low risk of developing osteonecrosis of the jaws if the patient continues to take an antiresorptive agent. These concerns are based on recent animal studies that have demonstrated impaired long-term implant healing [79].

For patients who have taken an oral bisphosphonate for less than four years and have also taken corticosteroids or antiangiogenic medications concomitantly, the prescribing provider should be contacted to consider discontinuation of the oral bisphosphonate (drug holiday) for at least two months prior to oral surgery, if systemic conditions permit. The antiresorptive should not be restarted until osseous healing has occurred.

For those patients who have taken an oral bisphosphonate for more than four years with or without any concomitant medical therapy, the prescribing provider should be contacted to consider discontinuation of the antiresorptive for two months prior to oral surgery, if systemic conditions permit. The bisphosphonate should not be restarted until osseous healing has occurred.

In addition, patients with periodontal disease and dental abscesses are also at higher risk. Migliorati's study indicated that $84 \%$ of patients with BRONJ are affected also by periodontal disease [80]. Marx, et al. recommended a blood test, the serum C-terminal telopeptide test ( CTX ) on an empty stomach, in order to evaluate the risk of ONJ in patients who have been administered bisphophonates for longer than three years. Values obtained that are greater than $150 \mathrm{pg} / \mathrm{mL}$ permit any kind of surgery to be performed at minimum risk and without the need to suspend medication. When values lower than $150 \mathrm{pg} / \mathrm{mL}$ are obtained, then medication should cease for a period of between four and six months or an alternative treatment option involving other types of prosthesis should be sought [61]. However, the American Dental Association and others, indicate that the collagen type 1 crosslinked telopeptide may be of questionable value and is not based on strong clinical evidence $[81,82]$, as indicated in the paper by Flichy Fernandez, et al. in which BRONJ was observed in a patient with normal values of serum CTX [67]. Furthermore even Bagan do not find a direct correlation between the level of CTX and the number and the dimension of area of BRONJ (but in case of bisphosphonates taken intravenously) [83]. Therefore the use of systemic markers of bone turnover as a measure of BRONJ risk is not recommended although the research in this area is continuing $[84,85]$.

\section{Conclusion}

In conclusion, the analysis of the studies show that treatment with oral bisphosphonates does not affect osseointegration of dental implants and in most cases determine a low risk of BRONJ. However, more studies of dental implant placement in osteoporotic patients taking bisphosphonates orally need to establish risk assessment of this procedure in these kind patients.

\section{References}

1. NIH Consensus Statement "Osteoporosis Prevention, Diagnosis and Therapy". NIH Consensus Statement: Washington; 2000.

2. Compston J. Action Plan for the prevention of osteoporotic fractures in the European Community. Osteoporos Int. 2004; 15: 259-262.

3. Who are candidates for prevention and treatment for osteoporosis? Osteoporos Int. 1997; 7: 1-6.

4. Kanis JA. Assesment of bone mass. Textbook of Osteoporosis: Wiley
Blackweel; 1996

5. Kanis JA. Diagnosis of osteoporosis and assessment of fracture risk. Lancet. 2002; 359: 1929-1936.

6. Melton LJ $3^{\text {rd }}$, Atkinson EJ, O'Connor MK, O'Fallon WM, Riggs BL. Bone density and fracture risk in men. J Bone Miner Res. 1998; 13: 1915-1923.

7. Geelhoed EA, Prince RL. The epidemiology of osteoporotic fracture and its causative factors. Clin Biochem Revs. 1994; 15: 173-178.

8. Prince RL, Knuiman MW, Gulland L. Fracture prevalence in an Australian population. Aust J Public Health. 1993; 17: 124-128.

9. National Osteoporosis Foundation.

10. Solomon L. Osteoporosis and fracture of the femoral neck in the South African Bantu. J Bone Joint Surg Br. 1968; 50: 2-13.

11. Villa ML, Nelson L, Nelson D. Race, ethnicity and osteoporosis. Osteoporosis: St Louis MO Accademic Press; 2001.

12. Melton LJ $3^{\text {rd }}$, Kan SH, Wahner HW, Riggs BL. Lifetime fracture risk: an approach to hip fracture risk assessment based on bone mineral density and age. J Clin Epidemiol. 1988; 41: 985-994.

13. Stafford RS, Drieling RL, Hersh AL. National trendsin osteoporosis visits and osteoporosis treatment, 1988-2003. Arch Intern Med. 2004; 164: 1525-1530.

14. Felsenberg D, Boonen S. The bone quality framework: determinants of bone strength and their interrelationships, and implications for osteoporosis management. Clin Ther. 2005; 27: 1-11.

15. Lane NE. Epidemiology, etiology, and diagnosis of osteoporosis. Am J Obstet Gynecol. 2006; 194: S3-11.

16. Grinspoon S, Thomas E, Pitts S, Gross E, Mickley D, Miller K, et al. Prevalence and predictive factors for regional osteopenia in women with anorexia nervosa. Ann Intern Med. 2000; 133: 790-794.

17. Otomo-Corgel J. Osteoporosis and osteopenia: implications for periodontal and implant therapy. Periodontol. 2000. 2012; 59: 111-139.

18. Marx RE, Sawatari Y, Fortin M, Broumand V. Bisphosphonate induced exposed bone (osteonecrosis/osteopetrosis) of the jaws: risk factors, recognition, prevention, and treatment. J Oral Maxillofac Surg. 2005; 63: 1567-1575.

19. Nussbaum SR, Younger J, Vandepol CJ, Gagel RF, Zubler MA, Chapman R, et al. Single-dose intravenous therapy with pamidronate for the treatment of hypercalcemia of malignancy: comparison of 30-, 60-, and 90-mg dosages. Am J Med. 1993; 95: 297-304.

20. Berenson JR, Hillner BE, Kyle RA, Anderson K, Lipton A, Yee GC, et al. American Society of Clin-ical Oncology clinical practice guidelines: the role of bisphospho-nates in multiple myeloma. J Clin Oncol. 2002; 20: 3719.

21. Physicians' Desk Reference. 57th ed. Montvale, NJ: Medical Eco $\neg$ nomics; 2003.

22. Delmas PD, Meunier PJ. The management of Paget's disease of bone. $\mathrm{N}$ Engl J Med. 1997; 336: 558-566.

23. Letocha AD, Cintas HL, Troendle JF, Reynolds JC, Cann CE, Chernoff $E J$, et al. Controlled trial of pamidronate in children with types III and IV osteogenesis imperfecta confirms vertebral gains but not short-term functional improvement. J Bone Miner Res. 2005; 20: 977.

24. Watts NB. Bisphosphonate treatment of osteoporosis. Clin Geriatr Med. 2003; 19: 395-414.

25. Delmas PD1. The use of bisphosphonates in the treatment of osteoporosis. Curr Opin Rheumatol. 2005; 17: 462-426.

26. Zarb GA, Schmitt A. The longitudinal clinical of osseointegrated dental implants. The Toronto study. Part II: the prosthetic result. J Prosthet Dent. 1990; 64: 53-61.

27. Esposito M, Hirsch JM, Lekholm U, Thomsen P. Biological factors contributing to failures of osseointegrated oral implants. (II). Etiopathogenesis. Eur J Oral Sci. 1998; 106: 721-764. 
28. Pinheiro MM, Castro CM, Szejnfeld VL. Low femoral bone mineral density and quantitative ultrasound are risk factors for new osteoporotic fracture and total and cardiovascular mortality: a 5-year population-based study of Brazilian elderly women. J Gerontol A Biol Sci Med Sci. 2006; 61: 196-203.

29. Douglass CW, Shih A, Ostry L. Will there be a need for complete dentures in the United States in 2020? J Prosthet Dent. 2002; 87: 5-8.

30. Lindquist LW, Carlsson GE, Jemt T. A prospective 15-year follow-up study of mandibular fixed prostheses supported by osseointegrated implants. Clinical results and marginal bone loss. Clin Oral Implants Res. 1996; 7: 329-336.

31. Linder L, Carlsson A, Marsal L, Bjursten LM, Brånemark PI. Clinical aspects of osseointegration in joint replacement. A histological study of titanium implants. J Bone Joint Surg Br. 1988; 70: 550-555.

32. Dao TT, Anderson JD, Zarb GA. Is osteoporosis a risk factor for osseointegration of dental implants? Int J Oral Maxillofac Implants. 1993; 8 137-144.

33. Marx RE. Pamidronate (Aredia) and zoledronate (Zometa) induced avascular necrosis of the jaws: a growing epidemic. J Oral Maxillofac Surg. 2003; 61 1115-1117.

34. Ruggiero SL, Mehrotra B, Rosenberg TJ, Engroff SL. Osteonecrosis of the jaws associated with the use of bisphosphonates: a review of 63 cases. $J$ Ora Maxillofac Surg. 2004; 62: 527-534.

35. Coskun Benlidayi I, Guzel R. Oral bisphosphonate related osteonecrosis of the jaw: a challenging adverse effect. ISRN Rheumatol. 2013; 2013: 215034.

36. Kühl S, Walter C, Acham S, Pfeffer R, Lambrecht JT. Bisphosphonate-related osteonecrosis of the jaws--a review. Oral Oncol. 2012; 48: 938-947.

37. Hoff AO, Toth BB, Altundag K, Johnson MM, Warneke CL, Hu M, et al. Frequency and risk factors associated with osteonecrosis of the jaw in cance patients treated with intravenous bisphosphonates. J Bone Miner Res. 2008; 23: $826-836$

38. Assaf AT, Smeets R, Riecke B, Weise E, Gröbe A, Blessmann M, et al. Incidence of bisphosphonaterelated osteonecrosis of the jaw in consideration of primary diseases and concomitant therapies. Anticancer Res. 2013; 33 3917-3924.

39. Khan AA, Sándor GK, Dore E, Morrison AD, Alsahli M, Amin F, et al. Canadian Association of Oral and Maxillofacial Surgeons. Canadian consensus practice guidelines for bisphosphonate associated osteonecrosis of the jaw. J Rheumatol. 2008; 35: 1391-1397.

40. Serra MP, Llorca CS, Donat FJ. Oral implants in patients receiving bisphosphonates: a review and update. Med Oral Patol Oral Cir Bucal. 2008;13: E755-60.

41. Lazarovici TS, Yahalom R, Taicher S, Schwartz-Arad D, Peleg O, Yarom $\mathrm{N}$. Bisphosphonate-related osteonecrosis of the jaw associated with dental implants. J Oral Maxillofac Surg. 2010; 68: 790-796.

42. Jacobsen C, Metzler P, Rössle M, Obwegeser J, Zemann W, Grätz KW. Osteopathology induced by bisphosphonates and dental implants: clinical observations. Clin Oral Investig. 2013; 17: 167-75.

43. Tam Y, Kar K, Nowzari H, Cha HS, Ahn KM. Osteonecrosis of the jaw afte implant surgery in patients treated with bisphosphonates--a presentation of six consecutive cases. Clin Implant Dent Relat Res. 2014; 16: 751-761.

44. Advisory Task Force on Bisphosphonate-related Osteonecrosis of the Jaws. American Association of Oral and Maxillofacial Surgeons. American Association of Oral and Maxillofacial Surgeons position paper on bisphosphonate-related osteonecrosis of the jaws. J Oral Maxillofac Surg. 2007; 65: 369-376.

45. Marx RE. A decade of bisphosphonate bone complications: what it has taught us about bone physiology. Int J Oral Maxillofac Implants. 2014; 29: e247-58.

46. Assael LA. Oral bisphosphonates as a cause of bisphosphonate-related osteonecrosis of the jaws: clinical findings, assessment of risks, and preventive strategies. J Oral Maxillofac Surg. 2009; 67: 35-43.

47. Jeffcoat MK. Safety of oral bisphosphonates: controlled studies on alveolar bone. Int J Oral Maxillofac Implants. 2006; 21: 349-353.
48. Elad S, Yarom N, Khamaisi M. Re: implant placement with or without simultaneous tooth extraction in patients taking oral bisphosphonates: postoperative healing, early follow-up, and the incidence of complications in two private practices. Fugazzoto PA, Lightfoot WS, Jaffin R, Kumar A. ( Periodontol 2007; 78: 1664-1669). J Periodontol. 2008; 79: 584-585, author reply 585-586.

49. Grant BT, Amenedo C, Freeman K, Kraut RA. Outcomes of placing dental implants in patients taking oral bisphosphonates: a review of 115 cases. J Oral Maxillofac Surg. 2008; 66: 223-230.

50. Bell BM1, Bell RE. Oral bisphosphonates and dental implants: a retrospective study. J Oral Maxillofac Surg. 2008; 66:1022-1024

51. Kasai T, Pogrel MA, Hossaini M. The prognosis for dental implants placed in patients taking oral bisphosphonates. J Calif Dent Assoc. 2009; 37: 39-42.

52. Koka S, Babu NM, Norell A. Survival of dental implants in post-menopausa bisphosphonate users. J Prosthodont Res. 2010; 54: 108-111.

53. Shabestari GO, Shayesteh YS, Khojasteh A, Alikhasi M, Moslemi N, Aminian A, et al. Implant placement in patients with oral bisphosphonate therapy: a case series. Clin Implant Dent Relat Res. 2010; 12: 175-180.

54. Famili P, Quigley S, Mosher T. Survival of dental implants among postmenopausal female dental school patients taking oral bisphosphonates: a retrospective study. Compend Contin Educ Dent. 2011; 32: 106-109.

55. Zahid TM, Wang BY, Cohen RE. Influence of bisphosphonates on alveolar bone loss around osseointegrated implants. J Oral Implantol. 2011; 37: 335346

56. Memon S, Weltman RL, Katancik JA. Oral bisphosphonates: early endosseous dental implant success and crestal bone changes. A retrospective study. Int J Oral Maxillofac Implants. 2012; 27: 1216-1222.

57. Mozzati M, Arata V, Giacomello M, Del Fabbro M, Gallesio G, Mortellaro $C$, et al. Failure risk estimates after dental implants placement associated with plasma rich in growth factor-Endoret in osteoporotic women under bisphosphonate therapy. J Craniofac Surg. 2015; 26: 749-755.

58. Tallarico M, Canullo L, Xhanari E, Meloni SM. Dental implants treatment outcomes in patient under active therapy with alendronate: 3-year follow-up results of a multicenter prospective observational study. Clin Oral Implants Res. 2015; 14.

59. Brooks JK, Gilson AJ, Sindler AJ, Ashman SG, Schwartz KG, Nikitakis NG Osteonecrosis of the jaws associated with use of risedronate: report of 2 new cases. Oral Surg Oral Med Oral Pathol Oral Radiol Endod. 2007; 103: 780 786

60. Wang HL, Weber D, McCauley LK. Effect of long-term oral bisphosphonates on implant wound healing: literature review and a case report. J Periodontol. 2007; 78: 584-594

61. Marx RE, Cillo JE Jr, Ulloa JJ. Oral bisphosphonate-induced osteonecrosis: risk factors, prediction of risk using serum CTX testing, prevention, and treatment. J Oral Maxillofac Surg. 2007; 65: 2397-2410.

62. Yarom N, Yahalom R, Shoshani Y, Hamed W, Regev E, Elad S. Osteonecrosis of the jaw induced by orally administered bisphosphonates: incidence, clinical features, predisposing factors and treatment outcome. Osteoporos Int. 2007; 18: $1363-1370$

63. Martin DC, O'Ryan FS, Indresano AT, Bogdanos P, Wang B, Hui RL, et al. Characteristics of implant failures in patients with a history of oral bisphosphonate therapy. J Oral Maxillofac Surg. 2010; 68: 508-514.

64. Marx RE. Oral and intravenous, in Bisphosphonates induced Osteonecrosis of the Jaws: History, Etiology, Prevention and treatment. Hanover Park II; Quintessence: 2009.

65. Park W, Kim NK, Kim MY, Rhee YM, Kim HJ. Osteonecrosis of the jaw induced by oral administration of bisphosphonates in Asian population: five cases. Osteoporos Int. 2010; 21: 527-533.

66. Bedogni A, Bettini G, Totola A, Saia G, Nocini PF. Oral bisphosphonateassociated osteonecrosis of the jaw after implant surgery: a case report and literature review. J Oral Maxillofac Surg. 2010; 68: 1662-1666. 
67. Flichy-Fernández AJ, González-Lemonnier S, Balaguer-Martínez J Peñarrocha-Oltra D, Peñarrocha-Diago MA, Bagán-Sebastián JV. Bone necrosis around dental implants: A patient treated with oral bisphosphonates, drug holiday and no risk according to serum CTX. J Clin Exp Dent. 2012; 4: 82-85.

68. Gupta R. Early dental implant failure in patient associated with oral bisphosphonates. Indian J Dent Res. 2012; 23: 298.

69. López-Cedrún JL, Sanromán JF, García A, Peñarrocha M, Feijoo JF, Limeres $\mathrm{J}$, et al. Oral bisphosphonate-related osteonecrosis of the jaws in dental implant patients: a case series. Br J Oral Maxillofac Surg. 2013; 51: 874-879.

70. Goss A, Bartold M, Sambrook P, Hawker P. The nature and frequency of bisphosphonate-associated osteonecrosis of the jaws in dental implant patients: a South Australian case series. J Oral Maxillofac Surg. 2010; 689: 337-343

71. Berardi D, Carlesi T, Rossi F, Calderini M, Volpi R, Perfetti G. Potentia applications of biphosphonates in dental surgical implants. Int J Immunopathol Pharmacol. 2007; 20: 455-465.

72. Volpi R, Rossi F, Trisi P, Testori T, Berardi D, Perfetti G. Pharmacologic modulation of clodronate in local therapy of periodontal and implant inflammation. Int J Immunopathol Pharmacol. 2007; 20: 69-74.

73. Zuffetti F, Bianchi F, Volpi R, Trisi P, Del Fabbro M, Capelli M, et al. Clinical application of bisphosphonates in implant dentistry: histomorphometric evaluation. Int J Periodontics Restorative Dent. 2009; 29: 31-39.

74. Zuffetti F, Testori T, Capelli M, Rossi MC, Del Fabbro M. The topica administration of bisphosphonates in implant surgery: a randomized splitmouth prospective study with a follow-up up to 5 years. Clin Implant Dent Relat Res. 2015; 17: 168-176.

75. Kumar MN, Honne T. Survival of dental implants in bisphosphonate users versus non-users: a systematic review. Eur J Prosthodont Restor Dent. 2012; 20: $159-162$.

76. Lo JC, O'Ryan FS, Gordon NP, Yang J, Hui RL, Martin D, et al. Prevalence of osteonecrosis of the jaw in patients with oral bisphosphonate exposure. J Oral Maxillofac Surg. 2010; 68: 243-253.
77. Background Document for Meeting of Advisory Committee for Reproductive Health Drugs and Drug Safety and Risk Management Advisory Committee. United States. Food and Drug Administration. 2011.

78. Ruggiero SL, Dodson TB, Fantasia J, Goodday R, Aghaloo T, Mehrotra B, et al. American Association of Oral and Maxillofacial Surgeons American Association of Oral and Maxillofacial Surgeons position paper on medicationrelated osteonecrosis of the jaw--2014 update. J Oral Maxillofac Surg. 2014; 72: 1938-1956

79. Kim I, Ki H, Lee W, Kim H, Park JB. The effect of systemically administered bisphosphonates on bony healing after tooth extraction and osseointegration of dental implants in the rabbit maxilla. Int J Oral Maxillofac Implants. 2013; 28: 1194.

80. Migliorati CA, Casiglia J, Epstein J, Jacobsen PL, Siegel MA, Woo SB. Managing the care of patients with bisphosphonate-associated osteonecrosis: an American Academy of Oral Medicine position paper. J Am Dent Assoc. 2005; 136: 1658-1668.

81. Koka S. Osteonecrosis of the jaw and biomarkers: what do we tell our patients? Int J Oral Maxillofac Implants. 2008; 23: 179-180.

82. Edwards BJ, Hellstein JW, Jacobsen PL, Kaltman S, Mariotti A, Migliorati CA. Expert Panel Reccomendations: Dental Management of Patients on Oral Bisphosphonates Therapy. Report of the Council on Scientific Affairs. J Am Dent Assoc. 2008: 137; 1144-1150.

83. Bagan JV, Jiménez Y, Gómez D, Sirera R, Poveda R, Scully C. Collagen telopeptide (serum CTX) and its relationship with the size and number of lesions in osteonecrosis of the jaws in cancer patients on intravenous bisphosphonates. Oral Oncol. 2008; 44: 1088-1089.

84. Mehrotra B, Fantasia J, Ruggiero SL. Outcomes of bisphosphonate related osteonecrosis of the jaw. Importance of staging and management. A large single institution update. J Clin Oncol. 2008; 26: 20526.

85. Dimopoulos MA, Kastritis E, Bamia C, Melakopoulos I, Gika D, Roussou $\mathrm{M}$, et al. Reduction of osteonecrosis of the jaw (ONJ) after implementation of preventive measures in patients with multiple myeloma treated with zoledronic acid. Ann Oncol. 2009; 20: 117-120
Austin J Dent - Volume 4 Issue 3 - 2017

ISSN : 2381-9189 | www.austinpublishing group.com

Nuti et al. ( ) All rights are reserved
Citation: Nuti N, Baldini N, D'Elia C, Gabriele G, Gennaro P and Ferrari M. Dental Implants in Osteoporotic Patients Taking Oral Bisphophonates: A Literature Review. Austin J Dent. 2017; 4(3): 1071. 